\title{
Estrategias autorreferenciales en tres relatos de Medardo Fraile
}

\author{
Grupo Seminario Fraile ${ }^{\mathrm{I}}$ \\ Universidad de Zúrich
}

\begin{abstract}
Por medio del análisis discursivo de los relatos «Las personas mayores», «El preso» y «El caramelo de limón» de Medardo Fraile, publicados en su antología Cuentos de verdad (1964), este artículo se propone estudiar algunas de las diferentes estrategias autorreferenciales con las que Fraile construye el sentido implícito de sus textos, de carácter metaliterario y escasamente considerado por la crítica hasta el momento.
\end{abstract}

Keywords: Medardo Fraile, Cuentos de verdad, cuento español del siglo xx, autorreferencialidad, iconografía, lectura implícita, «Las personas mayores», «El preso», «El caramelo de limón».

«Mi obra tiene mucho de desdoblamiento, de espejo, de piel que la culebra deja en el campo»

Medardo Fraile

\section{Preliminares}

El aspecto más destacado por la crítica en las narraciones de Fraile ha sido su trasfondo biográfico, algo que el autor jamás ocultó (Fraile 2000: I4). Sin embargo, lo universal y común al ser humano es asimismo intrínseco a su narrativa. "Decirlo todo sin contarlo» (Bellver 20II), así define Fraile el ingrediente principal de sus cuentos. Al principio de verdad, que rige la mayoría de sus relatos, se opone el misterio ${ }^{2}$. Por eso, desempeña un papel importante la dicotomía «decir-callar» o, en palabras de Fraile, «voz-eco», inherente a todo buen cuento: «Los ecos dan consistencia real a los personajes y a las situaciones en que se encuentran» (Bellver 20II). Su amiga y compañera de generación, Carmen Martín Gaite, destaca la destreza de Fraile para «el diálogo esencial (donde nada se explica y todo se sugiere)» y con-

I Ester Diez Ramos, Nina Kaderk, Katerina Kirova, Chiara Licci, Marija Nikolić y Patrick Santos Rebelo son los integrantes del Grupo Seminario Fraile, que ha realizado este estudio bajo la dirección de la Prof. Dra. Itzíar López Guil del Romanisches Seminar de la Universidad de Zúrich.

2 Según Fraile, la verdad de sus cuentos consiste en «las muchas verdades, mentiras y misterios, sospechados e insospechados, que hay en todos nosotros» (Bellver 20II). Afirma que «[sus textos] estaban sacados de vidas auténticas, [...] historias escuchadas con buen oído, sin falsificar» (Lanzas 20I4). En cambio, con el concepto del misterio se refiere a las «leyes [...] que [...] rigen el cuento [que] se va manejando solo, y eso es algo que debemos respetar» (Lanzas 20I4). 
sidera esta dinámica entre lo visto y lo adivinado una de las características cruciales del cuento como género literario (I998: I).

El propio Medardo publicó, también, varios textos metadiscursivos y, en varias entrevistas, desveló sus ideas sobre el género cuentístico, que se caracteriza, principalmente, por la brevedad y un idioma sobrio pero expresivo (Chiappe 2004). A pesar del frecuente uso del sarcasmo, que sirve para «quitar peso» (Chiappe 2004) a lo escrito, Fraile define el relato como una construcción sincera: «El cuento apura la verdad tanto que resulta pueril. Es esforzado, ya antes de nacer, porque busca al niño en el hombre -por eso muchas veces se pierde-» (I954). Esta búsqueda, siempre fallida y renovada en la vida, que representa un topos recurrente de sus cuentos, evidencia su interés por lo humano más que por la situación social o política3. Fraile pretende crear textos universales abordando temas no ligados a un contexto espacial o temporal concretos (Lanzas 20I4), relatos que conciernen a cada individuo. De hecho, este aspecto distingue los cuentos medardianos de los de sus contemporáneos, convirtiéndolo en un caso peculiar dentro de la generación del 50 (Quintana 2007: 59I). Sus personajes comparten la sencillez como rasgo característico: son seres humanos «frustrados o sin destino, frágiles [...] empleados en trabajos modestos» (Merino 2012: 56). A pesar de representar en sus textos situaciones cotidianas, la realidad de sus cuentos conlleva frecuentemente "algo de magia, de misterio», derivado de su creencia en un «realismo parcial o impuro de contenidos inexplicables, que unas veces se hacen visibles y otras no» (Ruiz de Huydobro 20I6: I47).

Fraile es un autor con una especial preocupación por la forma, incluso visual, de sus textos y por la imbricación de este plano con el del contenido (Domene 20I8: 199). En una anécdota referente a la publicación de su primer libro, Cuentos con algún amor (I954), Medardo da cuenta de cómo, por un error de un aprendiz, tuvo que «añadir un párrafo al principio de un cuento para que, en vez de empezar en página par, comenzara en la página impar anterior» (Ruiz de Huydobro 2016: I45). Aunque parezca un detalle insignificante, el autor maldijo «la irresponsable idea que [...] un impresor tenía del género cuento» (I45). El disgusto derivado de este episodio pone de manifiesto indirectamente la fundamental importancia que Medardo Fraile concedía a la disposición gráfica de sus cuentos, a menudo soporte de embragues textuales que, como veremos, conectan el nivel de sentido literal con el sentido implícito y metaliterario del relato. Algo que el cuentista y crítico Ángel Zapata, que mereció los elogios de Fraile ${ }^{4}$, parece confirmar

3 En el prólogo de Cuentos con algún amor, Fraile afirma: «Hay una desazón en el hombre que puede ser, simplemente, la búsqueda [...] en la vida, del cuento lejano que nos contó la abuela» (Fraile 1954).

4 En una entrevista, Fraile alabó el prólogo de Zapata, calificándolo de «espléndido» (Lanzas 2014). Además, ha colaborado con él escribiendo el prólogo de La práctica del relato: manual de 
cuando señala que «un cuento de Medardo entraña siempre un complejo y variable dispositivo de enunciación; que se desdobla, por lo común, en dos planos distintos» (2004: 27). Como ha sugerido Irene Andres-Suárez, Fraile «es un excelente teórico, que conoce a la perfección los instrumentos característicos del género que practica» (I995: 359).

La mayor parte de la crítica, según se ha mencionado, concede importancia casi exclusiva al nivel explícito de sentido a la hora de interpretar los cuentos medardianos. Sin embargo, existen estudios recientes en los que se llama también la atención sobre el sentido implícito de su narrativa:

En la textura de sus cuentos se muestra su especial capacidad para la evocación y su aptitud sugerente que nos lleva más allá del relato; elude la descripción directa y explícita de emociones, sensaciones o sentimientos fuertes, todo está implícito para que el lector se embarque en la imaginación y la sensibilidad adherentes al cuento, y cuando el escritor se ve descubierto, emplea el humor y la ironía como armas distanciadoras (Domene 20I8: I2I) ${ }^{5}$.

Pese a invitar, de esta manera a una lectura que trascienda el enunciado, Domene no alega ejemplos concretos. A continuación, pretendemos mostrar algunas de las estrategias textuales, a través de las cuales se manifiesta el nivel implícito en la narrativa de Fraile, tomando como objeto de análisis «Las personas mayores» de la colección Cuentos con algún amor (I954), así como «El preso»y «El caramelo de limón» de A la luz cambian las cosas (I959) ${ }^{6}$.

En una conferencia sobre el cuento, Fraile explica la función del título, cuya elección suele situarse en la última fase del proceso creativo ${ }^{7}$. Además, le otorga cierta importancia enunciativa al afirmar que «el cuento cien por cien comienza ya a contar en el título» (Fraile 1995: 23I). Efectivamente, por su situación liminar, previa al cuerpo del cuento, aun cuando forme parte de él, y su carácter metadiscursivo, el título posee un carácter híbrido en el que reside su potencial semiótico:

[...] el título pone de relieve determinado aspecto formal y/o semántico que confiere una suerte de identidad única a la composición. Al designarla por anticipado, el título se perfila entonces como un apéndice textual, capaz de ampliar descriptivamente el contenido [del cuento] y fijar las pautas de lectura que previamente determina la instancia autorial. Por lo tanto, el meta-

estilo literario para narradores (Zapata 2008).

5 La cursiva en las citas es siempre nuestra.

6 Ambas antologías forman parte de la edición de María del Pilar Palomo (200o).

7 Según Fraile, el «título [...] puede esperar y quizá sea más prudente pensarlo cuando el cuento esté escrito, aunque puede surgir antes, por supuesto, y, si es afortunado, condicionar incluso ligeramente la historia aún nonata» (I995: 231). 
discurso interpretativo que surge de este entrecruzamiento suscita en el [texto] ciertas expectativas, capaces de provocar en el lector enigmas sobre su significado y proponer incluso instrucciones para su cabal comprensión (Fröhlicher 2020: 239-240).

El título supone el primer contacto del lector con el cuento y forma junto con el texto una totalidad integral. Pertenece a una instancia enunciativa jerárquicamente superior a aquella que habla en el cuerpo del relato, nombra el texto (estableciendo implícitamente una relación de equivalencia con él) y constituye una «instrucción macrolingüística de expectativas» (Weinrich 1976: 17). Por tales motivos, resulta pertinente diferenciar en nuestro análisis de cada uno de los tres cuentos dos macrosecuencias discursivas diferentes: el título (A), por un lado, y el cuerpo del relato (B), por otro. A continuación, en cada cuento examinaremos demarcadores discursivos como el espacio, el tiempo o la voz narrativa, destacando las frecuentes coincidencias que el texto establece entre el plano de la expresión y el plano del significado, así como entre enunciado y enunciación, volviendo fuertemente icónicos algunos pasajes del texto y, consecuentemente, autorreferenciales.

Una estrategia recurrente en los cuentos de Fraile, a la cual dedicaremos especial atención, es la mirada. Como es sabido, en su uso se presenta una fuerte correlación con el pensamiento sartreano (Sartre 1954). Según el filósofo francés, la mirada ajena proporciona la afirmación de la identidad del individuo, rechazando así el solipsismo y poniendo el foco en lo social, en el otro. Esto le parece esencial porque el cogito individual solo tiene noticia de sí mismo en la medida en que el otro lo capta, lo valora, lo estima o detesta: «me ven, luego soy» (Sartre 1977). La presencia del otro es, por lo tanto, necesaria para nuestra autoconciencia. En la narrativa de Fraile, la mirada se presenta como sustancial para su poética:

[L]a mirada del escritor auténtico es anterior a la escritura; y la escritura [traduce] esa mirada del escritor. Hay una especie de digestión del ojo que resulta en algo diferente a lo que hacen los demás porque, naturalmente, cada uno ve de forma distinta (Lanzas 20I4).

Por consiguiente, la mirada desempeña un papel primordial en el proceso creativo, ya que los ojos digieren la realidad transformándola, por medio del lenguaje, en ficción (Lanzas 20I4, Fraile 2000: 16). 


\section{«Las personas mayores»}

En el segmento discursivo Bi.I de este cuento, desde su inicio hasta «[...] pensaban los críos» (Fraile 2000: 130), todas las "personas mayores» (I3I) integran un colectivo que supone un obstáculo para el juego infantil en el recodo del parque. Excepción son las niñeras, el hombre de los globos y un misterioso hombre al que se dedica la segunda macrosecuencia (BI.2 desde «No habían caído [...]» (I32) hasta el penúltimo párrafo), pues permite que los niños jueguen y se amolda a las exigencias de su fantasía. En el último párrafo (B2), cuando los niños ya se han vuelto adultos, el hombre pierde para ellos todo misterio.

En la parte inicial (BI.I), el jardín es un espacio delimitado, «un modelo de urbanización» que aparece «entre las tarjetas postales» del quiosco (I3I). Esta reproducción en miniatura de la postal constituye una mise en abyme explícita, ya que establece un paralelismo entre las dos representaciones del parque: aquella fotográfica de la postal y la verbal descrita dentro de la caja tipográfica de la página, ambas rectangulares e impresas. Nótese, además, el carácter icónico del sintagma inicial «Aquel recodo» (I30), ubicado en el ángulo superior de la caja tipográfica, en su recodo izquierdo, haciendo coincidir el plano de la expresión con el del contenido y, de resultas, el enunciado con la enunciación. Asimismo, tanto el banco largo que rodea el parque como la disposición de las niñeras con «uniforme» (I3I) blanco alrededor de los niños, evocan un paralelismo visual con el margen cuadrangular que rodea la caja tipográfica y con los espacios en blanco de la página, respectivamente.

En Bi.2, el cuento cambia su focalización pasando de «aquel recodo del jardín» (130) a un personaje-espacio introducido por el mismo deíctico, «aquel hombre» (133). En vez de ser un obstáculo, se define como «puente» (I32) o «camino» (I33). Su peculiaridad, además de estar y no estar «sobre la tierra» (I32) y permanecer en el anonimato, se subraya al no insertarse en un tiempo lineal y, por ende, no ser mortal, según sugiere su ausencia en el obituario del «semanario» (133, I34), confiriéndole así cierto halo de atemporalidad. En el último párrafo (B2), se produce una cesura importante tanto espacial como temporal, ya que los niños han crecido, moviéndose ahora en lugares cerrados «fuera de los parques» (I34), reservados sobre todo a los adultos. Este colectivo, que forma el título del cuento, apenas se menciona en el cuerpo textual ${ }^{8}$. Al asumir una óptica infantil, la voz narrativa parece autoexcluirse de las personas mayores. Además, el uso de coloquialismos -«charla» (I32), «la Chana» (I33)- parece reivindicar la perspectiva infantil o la de las niñeras, que aún no son adultas, en detrimento de aquella de las personas mayores. Se recurre a expresiones como «-jclaaaro!-» (I32), para

8 Concretamente, son 22 de 157 líneas. 
reflejar el entusiasmo espontáneo de los pequeños, y a repeticiones anafóricas, que evocan la sintaxis argumentativa propia de la infancia ${ }^{9}$. En las dos únicas ocasiones en las que ocurre el discurso directo en el cuento (I30, I3I), el narrador cede la palabra a niños y niñeras, mientras que resume los pensamientos de las personas mayores (I3I). La capacidad de este colectivo de estorbar el juego infantil se manifiesta de forma visual y auditiva en el plano de la expresión mediante el profuso empleo de algunos signos de puntuación, sobre todo el punto y coma que, icónicamente, interrumpe el libre fluir de la oración justo cuando el texto expresa el cese momentáneo de la actividad lúdica infantil a causa de la presencia adulta: «El juego quedaba partido unos segundos; la risa, estrellada; la ilusión, distraída» (I3I). De igual manera que se dice metafóricamente que se pone «un guión al juego roto para que siguiese en una línea dis-tinta» (132), ese mismo signo se emplea aquí para quebrar la palabra y la oración, dejándola continuar en la siguiente línea ${ }^{\mathrm{IO}}$. Igualmente, los guiones medios que introducen los comentarios por parte del narrador discontinúan el texto: «el sonido -algo lejos- de una campana» (132). Estas interrupciones se evidencian además en la estructura del propio relato. Mientras que las partes dedicadas a las personas mayores impiden el libre fluir de las líneas del cuento por su disposición discontinua, el hombre-puente no solo une las partes de la infancia (BI.I) y de la edad adulta (B2), sino también el principio con el final del texto. Asimismo, el cuento crece paralelamente al crecimiento de los niños y acaba en el mismo párrafo en el que se menciona su transformación en adultos, lo cual constituye otro embrague textual entre el enunciado (lo que se dice) y su propia enunciación (cómo se dice).

Volvamos ahora a la primera parte del cuento donde se manifiestan diferencias graduales entre los primeros dos grupos de niños, «los críos» $\mathrm{y}$ «los mayores» (130 $)^{\mathrm{II}}$, quienes gracias a la fuerza imaginativa transforman cuanto les rodea en un «desierto enorme» 0 «la cubierta de un trasatlántico» (I30). Crean, entonces, espacios nuevos, a partir de una realidad visible, lo cual se equipara al proceso creativo descrito por Fraile. El primer grupo, los críos, siendo los más jóvenes, todavía no manchados por los paradigmas sociales que corrompen la esencia infantil del hombre, encarna el primer estado de la creación literaria: la conexión con el niño perdido. Mientras que el segundo, por tener «más edad» (I30) y ser más instruido -se menciona que va al «Instituto» (130) - representa la estructura, el ingenio necesario para dar

9 Véase: «Y todo por aquellos [...]», «La cosa era [...]», «Como si [...]» (Fraile 2000: 132).

Io A pesar de que la posición del guión difiere según las ediciones (en la de Páginas de Espuma (2004) divide la palabra ro-to), la interrupción sigue coincidiendo con el contenido de la frase.

II También se menciona a los «otros [...] más tradicionales» que, en cambio, juegan con formas prefijadas, «el cubito y la pala», sin ninguna aportación propia (Fraile 2000: 130). 
forma y coherencia al texto. Además, al primero, se le cede la primera intervención del cuento en discurso directo, otorgándole cierta superioridad y evidenciando una clave de lectura:

-Tata, tengo sed-decía uno de los niños.

-¡No le des agua, tonta, que estamos en el desierto...! (130).

De hecho, estas frases fijan el compromiso de los niños a atenerse a las reglas lúdicas acordadas -y el lector con ellos- a percibir su entorno con esa mirada creativa propia de la niñez. En cambio, la visión de las personas mayores resulta ser limitada en cuanto que reduce el parque «sencillamente» a «un sanatorio» (I3I), buscando una definición lógica ${ }^{12}$. En suma, al crecer, uno pierde paulatinamente la sensibilidad de ver el mundo como un niño. Es lo que efectivamente les pasa a los críos del cuento en B2, donde los juegos $^{13}$ infantiles se convierten en metáforas de una vida laboral competitiva. Este cambio escenifica el proceso de alienación del ser humano, con el cual se identifica también el lector.

Pero este cuento les ofrece, a todos los niños crecidos (personajes y lectores), un medio para regresar a la infancia: un puente, «aquel hombre». El texto permite, por lo tanto, al lector fungir como segunda extremidad de un puente comunicativo que empieza en el cuento. El hombre-puente, siendo anónimo, emblematiza cualquier personaje que «hemos conocido alguna vez en algún libro» (134) capaz de dejar espacio a nuestra fantasía ${ }^{14}$. Por consiguiente, podemos encontrar este puente siempre y cuando hagamos una lectura atenta, activando la ciclicidad del cuento y permitiéndole trascender.

Para concluir, cabe destacar que esta ciclicidad se introduce con la mención de las personas mayores en la última línea y en el título. Como creemos haber demostrado a lo largo del análisis, el texto establece un paralelismo entre el espacio del jardín y el del propio relato. Por ende, el título, junto al grupo que nombra, se considera un elemento fuera del cuerpo del cuento, cumpliendo su ubicación en la caja tipográfica aquella que le otorga el texto en el cierre: «fuera de los parques se tropieza [...] con las personas mayores» (I34).

I2 Para no incurrir en el mismo error, el texto invita al lector con un imperativo «Mira» (I3I) a observar mejor el espacio del jardín, o sea, el texto.

I3 El juego de «la dola con lique» (I34) consiste en saltar a otro jugador agachado en el suelo (el burro), apoyando en él únicamente las manos. El lique es un juego en el que hay que dar una patada en el trasero al burro una vez que se ha saltado.

I4 Este albedrío infantil se ejemplifica en el cuento con el personaje de Pedrito, al cual se le concede la libertad de apodar al hombre alto cambiando el nombre del «Perro Negro» de $L a$ isla del tesoro por «Gato Negro» (Fraile 2000: 133). 


\section{«El preso»}

En el cuento «El preso», Jeremías está encarcelado por haber matado a una joven con un tulipán. Una tarde aburrida avista una nevatilla en el ventano de su celda, que entra, comunica con él visualmente y, tras esto, él se transforma en ave, lo que le permite evadirse volando. Al final, la nevatilla también sale de la cárcel con la ayuda del guardián.

Desde el comienzo del cuento asistimos a la cotidianidad de Jeremías en su celda, un espacio cerrado y delimitado. El cambio espacial del protagonista justifica la bipartición discursiva entre $\mathrm{Br}$ y B2 ${ }^{15}$. Ambas macrosecuencias no solo ponen en escena las dicotomías «interior-exterior», "cerrado-abierto», «preso-libre», sino también «inercia-acción» ${ }^{16} \mathrm{e}$ «incomunicación-comunicación». A pesar del uso de un tiempo verbal puntual, en un marco temporal terminado, el narrador omnisciente pierde la noción del tiempo en esta escena: «Así estuvieron qué sé yo el tiempo», exhibiendo así la peculiaridad de este pasaje (Fraile 2000: 15I-I52). Mediante el inciso qué sé yo, adscribible al habla coloquial, el narrador dirige nuestra atención hacia sí, revelándose un yo-narrador e instaurando cierta cercanía con el lector. De manera contraria, la frase irónica al final del cuento sirve de arma distanciadora: «Casi nada: jreducir el tamaño de un preso y enseñarle a volar...!» (I53). Efectivamente, la escena de la transformación merece una particular atención y, más precisamente, la confrontación con el episodio del tulipán. Antes de pasar a ello, cabe evidenciar algunos embragues textuales que corroboran el paralelismo entre la cárcel y la caja tipográfica de la página. Las líneas negras del texto sobre el papel blanco parecen ser emuladas por los barrotes de la ventana de la celda donde se encuentra Jeremías, tras los cuales nieva. Esta similitud metonímica se advierte también entre la nevatilla, que es de color «blanco y ceniciento» con «rayitas blancas en sus alas», y el preso con su «traje a rayas» (I5I). El hecho de que en «El preso» la celda se ubique en el «último piso» ${ }^{17}(\mathrm{I} 50)$ y esto se mencione precisamente en el punto más alto de la caja tipográfica, en la primera línea del cuento, es otra estrategia autorreferencial para equiparar el espacio de la prisión al del texto. Asimismo, los copos blancos de nieve, por encontrarse fuera de la cárcel, representan el borde blanco de las páginas. Además, el abandono de la celda por parte de Jeremías y el pájaro, dirigiéndose hacia el cielo (I52), está marcado grá-

I5 B2 comienza a partir de «Un pájaro vino [...]» hasta el final (I5I).

I6 La inercia se materializa, junto a los bostezos de Jeremías y al lento caer de la nieve, con el uso predominante de los tiempos verbales imperfectivos, mientras que la acción se expresa con el indefinido y aparece durante la narración de elementos dinámicos y fantásticos (entre los cuales se incluyen: la anécdota del tulipán, el encuentro entre Jeremías y el pájaro, la transformación del primero y el encuentro entre el pájaro y el cancerbero).

17 Según Bachelard, «la casa es imaginada como un ser vertical», ya que la parte superior representa la cabeza y así la consciencia (2000:38). 
ficamente con un final de línea anticipado, ilustrando así sus evasiones del cuento.

Regresemos ahora a los dos encuentros que evidencian un cambio en la mirada del protagonista: el motivo por el cual Jeremías está encarcelado radica en su mirada superficial que confía en el aspecto exterior de la flor «tan hermosa por fuera», pero que «en su interior, había segregado una gran piedra como un cáncer» (I50). En el segundo segmento, en cambio, la mirada atenta y concienzuda le permite imitar los movimientos del pájaro y comunicarse con él, estableciendo un paralelismo entre los dos personajes. No es casualidad que el verbo mirar se emplee con alta frecuencia en este último encuentro.

Como se mencionó arriba, la influencia sartreana de la mirada ${ }^{18}$, que abre la puerta a la comunicación, constituye un pilar vital en la poética de Fraile. Justamente en el encuentro entre Jeremías y el pájaro se pone de manifiesto cómo la mirada propicia la interacción. Al referirse al cuento «Una camisa», Roger afirma que «[l]a mirada ayuda a la comprensión, cuando no es posible comunicarse en una lengua común» (I997: 404). Aquí, la comunicación se desarrolla mediante los movimientos: «daba saltitos imitándola» (Fraile 2000: 15I). Al observarse, ambos reconocen sus semejanzas. Se desencadena un proceso de autopercepción y asimilación que culmina en la transformación física del protagonista ${ }^{19}$.

Ocurre todo lo contrario en $\mathrm{BI}$, durante el encuentro con la «criatura angelical rubia» $(150)^{20}$. En este fallido acto de comunicación, la receptora se niega a aceptar el tulipán; y los alegres golpecitos que le da Jeremías para persuadirla tienen fatales consecuencias. Porque el tulipán, pese a su bella apariencia, tiene una dura y terrible esencia escondida y es figura de una literatura que, al no hacer coincidir forma y contenido, resulta mortal para el lector y conduce a un fracaso comunicativo. Además, Jeremías es aquí un mal lector porque no decodifica la esencia de la flor y se deja engañar por su apariencia. Sin embargo, en el segundo encuentro, emplea la mirada como medio de comunicación. Se convierte en un buen lector y alcanza su libertad, perdida como consecuencia de su mala lectura y su fallida comunicación. Esta mirada es necesaria para que el acto comunicativo se cumpla. Por lo tanto, cuando el pájaro salta a la ventanilla, su interlocutor -tal como los niños en «Las personas mayores»- tiene que seguir las reglas del

I8 Véase Sartre, «La mirada», cap. IV de El ser y la nada (1954).

I9 En el segmento BI (Fraile 2000: 15I), quizás como presagio, se usa otro pájaro para describir a Jeremías: la gallina. Un ave que, contrariamente a la nevatilla, no vuela tan alto ni sabe cantar, y que coloquialmente se relaciona con la cobardía (ser un gallina).

20 En el encuentro posterior con el pájaro se hallan ecos de esta escena: el mismo estado de ánimo «divertido» de Jeremías y el uso del diminutivo «golpecitos» (I50) que se asemejan a los «saltitos» (I5I). 
juego que acaban de fijar (su pacto de ficción) y que se basan en la empatía y la identificación recíproca. De este modo, se sitúan «a la misma altura» (I52), permitiendo al preso, mientras vuela, compartir el mismo espacio supraterrenal que el animal: el cielo, espacio de la trascendencia, asimilable al de la literatura. El encuentro propicio se puede interpretar, finalmente, como mise en abyme del acto de comunicación entre lector y texto, en el que el lector logra empatizar y asimilar lo escrito, de modo que el texto trasciende y el lector deja temporalmente su espacio habitual para adentrarse en el espacio ficticio de la literatura.

Por último, al igual que en «Las personas mayores», se observa una incongruencia semántica entre título y texto. Esta se materializa con la evasión del protagonista de la cárcel, dejando en manos del lector la pregunta sobre quién es de verdad el preso en este cuento: el relato (B) escenifica tipográficamente la fuga literal del título «El preso» (A) de la cárcel y del texto, dejando a un único actor al final de B -el carcelero, preso de su incapacidad comunicativa e imaginativa- que ocupa a la vez el espacio de la cárcel y la caja tipográfica, de los que tanto Jeremías como la nevatilla se han evadido.

\section{«El caramelo de limón»}

El protagonista de «El caramelo de limón» es un vendedor a domicilio de artículos de mercería, que un día, al salir de la casa de un cliente, se encuentra mareado y decide regresar a su casa. En el camino se detiene en el quiosco de una anciana y le compra tres caramelos. Al llegar a su casa, se describe su vida matrimonial, dominada por la enfermedad y pasividad de su mujer Pilar. Sin embargo, con la ayuda del caramelo logra redimir su frustración cotidiana al trasladarse mentalmente a sus días infantiles.

El relato es un monólogo interior ${ }^{21}$ de un narrador autodiegético, con algunos diálogos parciales ${ }^{22}$. De esta manera, frente a la información filtrada únicamente por los sentidos del protagonista, al lector no le queda más remedio que empatizar con la voz narrativa. Se deja guiar desde un espacio abierto y social, hacia uno cerrado y reservado exclusivamente a la presencia del yo. Por consiguiente, la evolución del protagonista está estrechamente ligada al movimiento espacial, que refleja al mismo tiempo el cambio del mundo exterior al interior tanto en el aspecto interactivo como en el psicológico. Mientras que en $\mathrm{BI}^{23}$ el narrador se comunica en la calle con la anciana vendedora y los vecinos del barrio, así como con su esposa

2I El monólogo interior es «[...] un truco [...] para hacerle creer al lector que tiene acceso directo a los pensamientos de los protagonistas» (Andres-Suárez I995: 365).

22 En el enunciado del protagonista se infieren las respuestas de los demás: «-¡Pilar! [...] Que sí, mujer, que ya lo sé» (Fraile 2000: I72).

23 BI va desde el inicio del cuento (I68) hasta «El catre» (I73), donde comienza B2. 
Pilar en el piso (Fraile 2000: I69-I72), en B2 se encuentra aislado en el catre, su microcosmos, en el cual comienza a dialogar consigo mismo ${ }^{24}$. La intimidad de este espacio junto con el «caramelo de limón proustiano» (Izard 20I6: I73) le posibilita la confrontación con su yo del pasado, permitiéndole revivir su infancia. En resumen, la llegada al catre, al que el narrador define como «un viejo y fiel amigo» (Fraile 2000: 173), le da un sentido de libertad incluso antes de comer la golosina: «me encuentro en él libre, muy libre, como un navegante solitario ${ }^{25}$ (I73). Asimismo, el malestar tanto físico como psíquico de la primera parte se convierte aquí en alegría (173). Por lo tanto, la espacialidad del catre motiva el proceso mnemónico activado por el caramelo de limón.

Además de la influencia del entorno espacial y social, el protagonista posee una característica que resulta indispensable para su evolución: la mirada creadora. Sus ojos, en efecto, están dotados de un poder transformador. Esta capacidad se evidencia, ya desde el inicio, en la relación que el narrador mantiene con su maleta, ya que la antropomorfiza con su mirada. El objeto no solo comparte su estado de ánimo, sino que se convierte en su acompañante e interlocutor: «Miro mi maleta [...] y consulto con ella [...] la maleta y yo estamos cansados» (I68). En la cocina de su apartamento, el protagonista se sirve nuevamente de sus ojos para vivificar su entorno: personifica la comida, llamándola «exhausta» o «muy triste» (I72). Por último, humaniza también el caramelo, cuyo sabor «tiene algo que decir[le]» (I73), transformando nuevamente algo inanimado en su interlocutor. De hecho, el acto comunicativo se anticipa por la mirada del protagonista, ya que la digestión visual precede a la gustativa: observa primero el papel para después disfrutar del caramelo (173). Sin embargo, esta vez el cambio parece ser recíproco, ya que el dulce vivifica su yo pasado, posibilitando así el hallazgo del niño perdido en el acto de rememoración. Cabe señalar que el objeto que le permite este descubrimiento proviene de una «abuela» (I70), aludiendo así a aquel cuento de la abuela evocado en la poética medardiana (Fraile 1954). El protagonista, pese a ser adulto, ha conservado su mirada infantil ${ }^{26}$, creativa, que se muestra indispensable para beneficiarse del poder evocativo del caramelo.

El espacio no solo influye en la evolución del protagonista, sino que posee un significado simbólico, fuertemente icónico, que se manifiesta ya desde el inicio del cuento. De hecho, el portal funge de embrague textual: en la

$24 \mathrm{El}$ «charlar [...] con[s] igo mismo» (I69) aparece también como topos en «Retrato» de Machado: «[c]onverso con el hombre que siempre va conmigo» (2018: IO2).

25 En la tradición literaria occidental, la navegación simboliza, entre otros, la literatura o el proceso de escribir (Metzler 2008: 320).

26 El protagonista alude al fenómeno de la pérdida de la mirada infantil cuando describe su ilusión al comprar los caramelos: «Algunos perdemos esta compra para siempre, como si fuera sólo para los críos» (Fraile 2000: 170). 
primera frase, el protagonista se encuentra «en el portal de la casa» (Fraile 2000: I68) de una clienta, haciendo coincidir así la entrada de la casa con la entrada en el relato (hay, pues, una similitud entre enunciado y enunciación). Posteriormente se configura una situación similar cuando el narrador entra en su piso. El cierre de la puerta coincide con el cambio del subsegmento BI.I al BI..27, que marca la transición del espacio público al privado. Además, la escena que precede a este embrague textual llama la atención por constituir una mise en abyme de la enunciación. El narrador se altera por la curiosidad de su vecina, que le observa por la mirilla: «iBueno! Ya me has visto bien. ¿Cierro mi puerta ya?» (I7I). Al utilizar la segunda persona del singular por primera vez, parece dirigirse también al lector. De esta manera, se produce una analogía entre el enunciatario del texto y «la lechuza de enfrente» (I7I), puesto que ambos tienen en común una visión limitada de la realidad del protagonista. Lo que queda entre líneas o, figurativamente, detrás de la puerta cerrada, hay que interpretarlo.

Por lo tanto, no basta solo con fijarse en lo dicho o escrito, sino también en lo callado u omitido. El silencio abrupto, pero intencionado entre los esposos, queda representado en la tipografía, o mejor dicho, en el espacio en blanco: «Voy a hacerte compañía, aquí, en el catre, en silencio. Estoy algo cansado. El catre » (173). Además del silencio, el distanciamiento espacial del mundo social le permite al protagonista sumergirse en su microcosmos: el catre. El cambio se manifiesta, entonces, tanto en el nivel de enunciado como en el de enunciación. En este contexto, cabe destacar la brevedad de la palabra catre, frente al largo compuesto cama de matrimonio, que representa el lugar donde «navega» Pilar (I73). De esta manera, se visualiza también gráficamente la diferencia entre los dos espacios. A pesar de ser un lecho que, en general, es menos cómodo por su sobriedad y rusticidad, constituye un sitio reservado para el protagonista, permitiéndole el proceso creativo. Una vez más, se destacan aquí la brevedad y austeridad retóricas como rasgos cruciales de la narrativa breve de Fraile.

Por último, volvamos sobre la bipartición entre título y cuento que se fundamenta en la analogía entre la función que cumple el caramelo para el narrador y aquella que tiene para nosotros como lectores: el enunciado coincide con la enunciación, igualando así el acto mnemónico, que provoca el sabor del caramelo, al acto de lectura ${ }^{28}$. Ambos se caracterizan por su naturaleza efímera, puesto que la evocación tiene lugar solo mientras el sabor dura: al gastarse, termina el viaje mental concordando casi con el propio final del cuento y su lectura (I75). De este modo, el caramelo, todo dulzura y acidez, viene a representar un segmento temporal limitado que facilita la

27 La parte BI.I va desde el inicio del cuento (I68) hasta «Pilarín!» (I7I), donde comienza BI.2 que termina con «El catre» (I73).

28 Al leer activamos el contenido de un tiempo pasado insertándolo en uno presente. 
rememoración de vivencias pasadas, como lo consigue también el propio relato. El disfrute de la golosina permite activar la memoria del protagonista al igual que el lector actualiza el tiempo del cuento siempre y cuando goza de la lectura. «El caramelo de limón» se inserta así en el tiempo circular del arte, al que remite también la forma redonda del caramelo.

\section{Conclusiones}

Como esperamos haber mostrado en las páginas precedentes, son varias las estrategias autorreferenciales que Fraile emplea en sus cuentos para crear en ellos un segundo nivel de sentido metaliterario. Una de ellas es la instauración de un paralelismo entre los espacios del enunciado (el recodo de un parque, el último piso de la cárcel, el portal de una casa, etc.) y la propia caja tipográfica de la página, estableciendo una equivalencia entre enunciado y enunciación.

En los tres relatos se detecta también la presencia de una atemporalidad vinculada a elementos distintivos (el hombre misterioso, la nevatilla o el catre) que posibilitan la interacción entre los personajes. El alejamiento del tiempo lineal está ligado a la imaginación lúdica e infantil, metáfora de la comunicación literaria, la cual quiebra los paradigmas temporales para insertarse en un tiempo circular y trascender.

Abordamos también la mirada como otro aspecto característico de la narrativa medardiana que anticipa el proceso comunicativo. Además de condicionar el juego entre los niños o permitir el intercambio mimético entre animal y hombre, también precede al proceso mnemónico. Por lo tanto, la digestión del ojo, que antecede a la expresión verbal, remite al proceso creativo, en el cual la mirada es anterior a la escritura.

Finalmente, resaltamos la función del título: al desarticularlo del cuerpo narrativo, sirve de clave interpretativa para una lectura cabal. Sin embargo, el paralelismo entre título y cuento establecido por ironía o analogía, no se descubre hasta el final, obligándonos a releer el relato.

Por medio de estas estrategias autorreferenciales, la mirada infantil puede renacer durante la lectura para ser conservada en la vida adulta y real. $L a$ piel, que la culebra deja en el campo, remite, pues, al enunciado breve y denso en expresividad, invitando al lector a leer entre líneas e identificar las verdades, en su esencia, plurales. 


\section{Bibliografía}

Andres-Suárez, Irene, «Medardo Fraile, maestro en el arte de la evocación», Lucanor: Creaciones e investigación: Revista del cuento literario, 13 , I995, pp. 49-78.

Bachelard, Gaston, La poética del espacio, Buenos Aires, FCE, 2000.

Bellver, Sergi, «Cuentistas (I): Medardo Fraile», Revista de Letras, Barcelona, 20II, https://revistadeletras.net/cuentistas-i-medardo-fraile/ [08.0I.202I].

Butzer, Günter \& Joachim Jacob, Metzler Lexikon literarischer Symbole, Stuttgart, J. B. Metzler, 2008.

Chiappe, Doménico, "Cuando el cuento se convierte en gota de sangre», TalCual, Caracas, 2004, https://letralia.com/ciudad/chiappe/15.htm [08.0I.202I].

Domene, Pedro M., «Medardo Fraile o el arte de contar», Narrativas: revista de narrativa contemporánea en castellano, 49, 20I8, pp. II9-I22.

Fraile, Medardo, Cuentos con algún amor, ed. José María Cabezali, Madrid, Colección Literatura de Juglaría, 1954.

-. Cuentos de verdad, ed., María del Pilar Palomo, Madrid, Cátedra, 2000.

-. "Ciclo vital del cuento», Boletín de la Real academia Sevillana de Buenas Letras: Minervae Baeticae, 23, 1995, pp. 225-237.

Fröhlicher, Peter, «Virtudes del título en la obra poética de Octavio Paz», en El título del poema y sus efectos sobre el texto lírico iberoamericano, eds. Itzíar López Guil y Dayron Carrillo Morell, Berna, Peter Lang, 2020, pp. 239-256.

Izard, Yolanda, «Pequeñas subversiones: deconstrucción e impresionismo en los cuentos de Medardo Fraile», Quimera: Revista de literatura, 387, 20I6, pp. 3I-33.

Lanzas, Emilia, «Entrevista al maestro del cuento Medardo Fraile», ¡Zas! Madrid, Madrid, 20I4, https://zasmadrid.com/entrevista-al-maestro-del-cuento-medardo-fraile/ [Io.oI.202I].

López Guil, Itzíar, «El título de los poemas en la poesía española contemporánea», Versants, 3.66, 2019, pp. 5-6.

Machado, Antonio, Campos de Castilla, ed. Geoffrey Ribbans, Madrid, Cátedra, 2018.

Martín Gaite, Carmen, «Palabras mayores: sobre Contrasombras, de Medardo Fraile», Saber leer, I20, 1998, pp. I-2.

Merino, José María, «Sobre la narrativa de Medardo Fraile», Revista de la Academia Norteamericana de la Lengua Española, I.I/2, 2012, pp. 53-63.

Quintana, María Rosario, «Identidad e identidades en los cuentos de Medardo Fraile», en Las dos orillas: actas del XV Congreso de la Asociación Internacional de Hispanistas, Monterrey, México, del I9 al 24 de julio de 2004, coords. Beatriz Mariscal y María Teresa Miaja de la Peña, 4, México, Fondo de Cultura Económica, 2007, pp. 585-592. 
Roger, Isabel M., «La visión amorosa en algunos relatos de Carmen Martín Gaite y Medardo Fraile», Revista Canadiense de Estudios Hispánicos, 2I.2, I997, pp. 396-406.

Ruiz de Huydobro, Roberto, Antonio Ferres y Medardo Fraile, dos narradores del 50, Alicante, Biblioteca Virtual Miguel de Cervantes, 2016.

Sartre, Jean-Paul, El ser y la nada, Buenos Aires, Iberoamericana, $2^{\text {a }}$ ed., 1954.

-. Los caminos de la libertad, 2, Madrid, Aguilar, 1977.

Weinrich, Harald, Lenguaje en textos, Madrid, Gredos, 1976.

Zapata, Ángel, «La ternura del nómada. Una introducción a la poética de Medardo Fraile», en Escritura y verdad. Cuentos completos de Medardo Fraile, Madrid, Páginas Espuma, 2004, pp. 9-30. 